\title{
SISTEM ANALISA TINGKAT KEPUASAN MAHASISWA TERHADAP KEGIATAN BELAJAR MENGAJAR PADA PSTI UNRAM DENGAN MENGGUNAKAN METODE SERVICE QUALITY
}

\author{
(The Analysis System Students Satisfaction Level Toward Teaching and Learning \\ Process in PSTI Unram Using Service Quality Method) \\ Zakiyah Rahmiati, I Gede Pasek Suta Wijaya ${ }^{*}$, Budi Irmawati \\ Program Studi Teknik Informatika, Fakultas Teknik, Universitas Mataram \\ JI. Majapahit 62, Mataram, Lombok NTB, INDONESIA \\ Email: zakiyahrahmiati@gmail.com,gpsutawijaya@te.unram.ac.id, budi-i@unram.ac.id
}

\begin{abstract}
This paper presents a system for analyzing Student Satisfaction Level of teaching process in Informatics Engineering Dept., Mataram university using service quality (Servqual) method. The aim of this work is to provide a tool for knowing the quality of teaching process by assessing the performance of teaching through the online questionnaire. It can be done because the Servqual method has been successfuly for assessing the Satisfaction Level. Based on experimental results (Black-Box and Mean Opinion Score, MOS), the developed system for analyzing Student Satisfaction Level using service quality (Servqual) method has been work properly which indicated by all functionality of the sytem has expectedly run well and the MOS value of 40 sample is 4,15. By using this system, studens able to give the evaluation towards service provided during teaching and learning process, and PSTI Unram can receive the information about the analysis result of students satisfaction level towards the quality of service given.
\end{abstract}

Key words: Satisfaction Level, Service Quality, Black Box, Mean Opinion Score, Web-based system.

*Penulis korespondensi

\section{Pendahuluan}

Kegiatan Belajar Mengajar (KBM) merupakan hal yang sangat penting bagi para pelajar khususnya mahasiswa dalam proses memperoleh ilmu pengetahuan. Dengan mengikuti proses KBM, mahasiswa memperoleh wawasan mengenai suatu bidang ilmu tertentu. Mahasiswapun sangat menginginkan kemudahan dan kenyamanan dalam proses KBM agar mahasiswa dapat dengan mudah memahami ilmu yang diberikan. Pada kenyataannya proses KBM yang baik belum bisa dilihat dan dinilai secara kasat mata. Dalam hal menilai seberapa baik pelayanan KBM yang ada pada Program Studi Teknik Informatika Universitas Mataram (PSTI UNRAM), saat ini masih dilakukan pengisian kuisioner secara manual, karena belum memiliki sistem untuk mewadahi mahasiswa dalam memberikan penilaiannya terhadap KBM, sehingga proses analisa tingkat kepuasan mahasiswa masih berlangsung lama dan kurang efisien.

Dalam menganalisa tingkat kepuasan mahasiswa terhadap KBM ada beberapa metode yang dapat digunakan, salah satunya dengan menggunakan
Metode Service Quality (Servqual). Servqual merupakan metode yang digunakan untuk mengetahui jenis pelayanan seperti apa yang dapat mempengaruhi kepuasan mahasiswa sehingga harus lebih diperhatikan dalam upaya peningkatan kualitas KBM. Karena salah satu cara untuk menilai tingkat kepuasan mahasiswa, yaitu dengan mengidentifikasi seberapa besar persepsi mahasiswa mengenai pelayanan yang diterima dan harapan mahasiswa akan peningkatan kualitas.

Dari permasalahan tersebut dibutuhkan suatu sistem yang dapat mewadahi mahasiswa dalam memberi penilaian terhadap proses KBM, sehingga dapat dijadikan bahan evaluasi bagi PSTI UNRAM dalam meningkatkan kualitas KBM dan akreditasinya untuk menjadi lebih baik lagi. Oleh karena itu penulis membuat sistem untuk menganalisa tingkat kepuasan mahasiswa terhadap KBM pada PSTI UNRAM. Dengan demikian, dapat diketahui kepuasan mahasiswa terhadap hasil KBM, sehingga dapat dicarikan solusi yang tepat bagi permasalahan yang ada.

Sistem ini diharapkan dapat membantu mahasiswa dalam memberikan penilaian terhadap KBM demi 
kemajuan PSTI UNRAM, dan bagi PSTI UNRAM dapat meningkatkan kualitas pelayanan KBM-nya agar menjadi lebih baik lagi sehingga dapat menghasilkan alumni yang berkualitas.

\section{Tinjauan Pustaka}

Servqual adalah suatu metode yang dikembangkan oleh Berry, Zeithaml, dan Parasuraman digunakan untuk mengukur kualitas produk atau jasa, dimana harapan, kepuasan pelanggan, dan kualitas pelayanan mempunyai hubungan yang dapat diukur dari kualitas pelayanannya yang dihitung dengan membandingkan ekspektasi dan persepsi pelanggan. Untuk mengukur tingkat kepuasan berdasarkan persepsi dan harapan digunakan skala likert dimana angka 1 menunjukkan (sangat tidak puas), 2 (tidak puas), 3 (netral), 4 (puas), dan 5 (sangat puas)[1]. Sudah banyak bermunculan penelitian mengenai analisa tingkat kepuasan pelanggan terhadap pelayanan dengan berbagai metode seperti Importance and Performance Analysis (IPA), Service Quality (Servqual), dan Kano. Metode IPA digunakan untuk menganalisa kepuasan konsumen terhadap suatu perusahaan dengan membandingkan antara harapan dan kinerja[2]. Metode Kano digunakan untuk mengukur tingkat preferensi mahasiswa terhadap atribut layanan yang dikelompokkan dalam kategori Kano[2]. Metode Servqual adalah instrumen penelitian multidimensi yang didesain untuk mengukur kualitas layanan dengan memintai ekspektasi dan persepsi responden di antara lima dimensi kualitas layanan yaitu Reliability, Assurance, Tangibles, Empathy dan Responsiveness [2].

Analisis kepuasan konsumen dengan Servqual studi kasus bhinneka.com telah dilakukan menggunakan 28 atribut pertanyaan yang terdiri dari 5 dimensi kualitas pelayanan Servqual berdasarkan survey kepuasan konsumen tahun 2010 pada 100 responden. Hasilnya ditemukan bahwa konsumen masih belum puas, sehingga perusahaan masih memiliki ruang untuk meningkatkan performanya[3].

Penggunaan Metode Servqual untuk analisa kepuasan pusat oleh-oleh Harum Manis menggunakan esponden sebanyak 108 orang, diperoleh kesimpulan bahwa pelanggan merasa belum puas[4]. Penerapan metode Servqual dan Regresi Linear Berganda untuk analisa kepuasan Mahasiswa Teknik Mesin Universitas Malang dengan melibatkan respondense 55 orang, didapatkan bahwa nilai kepuasan lebih rendah dari harapan, sehingga disimpulkan mahasiswa Teknik Mesin Universtas Malang masih belum puas dengan pelayanan yang ada[1].
Penelitian tentang analisis kualitas pelayanan terhadap tingkat kepuasan pelanggan menggunakan metode Servqual juga telah berhasil dilakukan dengan cara wawancara dan menyebar kuisoner kepada pelanggan PT.BPR Armindo Kencana[5]. Sistem analisa dilakukan dengan aplikasi java dengan tampilan yang sederhana.

Berdasarkan metode-metode tersebut, dapat dinyatakan bahwa metode Servqual dapat digunakan untuk mengukur hubungan tingkat kepuasan mahasiswa dengan kualitas pelayanan dengan membandingkan persepsi dan harapan mahasiswa terhadap pelayanan KBM, khususnya studi kasus PSTI UNRAM. Metode Servqual dapat menggunakan soal kuesioner yang perancangannya terdiri dari banyak atribut pelayanan yang dikategorikan ke dalam 5 dimensi Servqual yang merupakan patokan dari kualitas pelayanan. Metode Servqual dapat menentukan kepuasan mahasiswa tiap atribut pelayanan maupun secara menyeluruh agar PSTI UNRAM dapat menentukan mana atribut pelayanan yang perlu diperbaiki, dipertahankan maupun diabaikan, sehingga di masa yang akan datang performa pelayanan yang diberikan menjadi lebih baik lagi agar kepuasan mahasiswa juga semakin meningkat. Data hasil kuesioner akan dianalisa menggunakan metode Servqual, memberikan output informasi berupa skor Servqual (indeks total kepuasan mahasiswa) dan juga grafik yang menunjukkan persentase kuadran atribut pelayanan berdasarkan persepsi dan harapan mahasiswa, dimana tiap kuadran dapat menentukan tingkat prioritasnya.

\section{Metode Penelitian}

Secara sederhana alur penelitian ini dilakukan seperti tertuang pada Gambar 1, yang terdiri atas berapa proses, yaitu:

a. Studi Literatur yang merupakan proses memperoleh data-data yang bersifat teoritis melalui buku-buku, literatur, ataupun jurnal yang berhubungan dengan masalah implementasi metode Servqual yang meliputi teori kepuasan, metode Servqual dan bagaimana langkah perhitungannya.

b. Pengumpulan Data, merupakan proses untuk memperoleh data untuk memberikan penilaian analisa tingkat kepuasan mahasiswa pada PSTI UNRAM ini maka penulis juga meminta dokumen pada lembaga penjaminan mutu Fakultas Keguruan dan IImu Pendidikan (FKIP) Universitas Mataram. Dokumen tersebut berbentuk angket atau daftar 
kuesioner analisa kepuasan mahasiswa terhadap proses pembelajaran. Disamping dilakukan juga pengamatan dari hasil pengisian kuesioner yang akan dilakukan oleh mahasiswa PSTI pada sistem analisa tingkat kepuasan mahasiswa terhadap KBM yang akan dibuat.

c. Analisis Kebutuhan Sistem, berdasarkan analisa alat dan bahan yang dibutuhkan dalam pembuatan sistem analisa tingkat kepuasan mahasiswa terhadap KBM pada PSTI UNRAM berbasis web ini meliputi :

a. Laptop ASUS Corel3 Processor Intel ${ }^{\circledR}$ Core $^{\mathrm{TM}}$ 13$3217 \mathrm{U}$ dengan RAM 2GB.

b. Sistem operasi Windows 7 Ultimate 32-bit.

c. Codelgniter sebagai framework dalam membangun sistem berbasis web.

d. MySQL phpmyadmin sebagai server database.

e. Google Chrome sebagai web browser.

f. Microsoft Visio sebagai media untuk merancang sistem.

g. Data mahasiswa, dosen, dan mata kuliah dari API Sistem Informasi Akademik Universitas Mataram (SIA

UNRAM: sia.unram.ac.id/_api/docs).

h. Poin-poin evaluasi kegiatan belajar mengajar berdasarkan masukan dari Tim Penjamin Mutu FKIP UNRAM.

i. Poin-poin kuesioner yang pernah diberikan mengenai penilaian terhadap kegiatan belajar mengajar pada PSTI UNRAM.

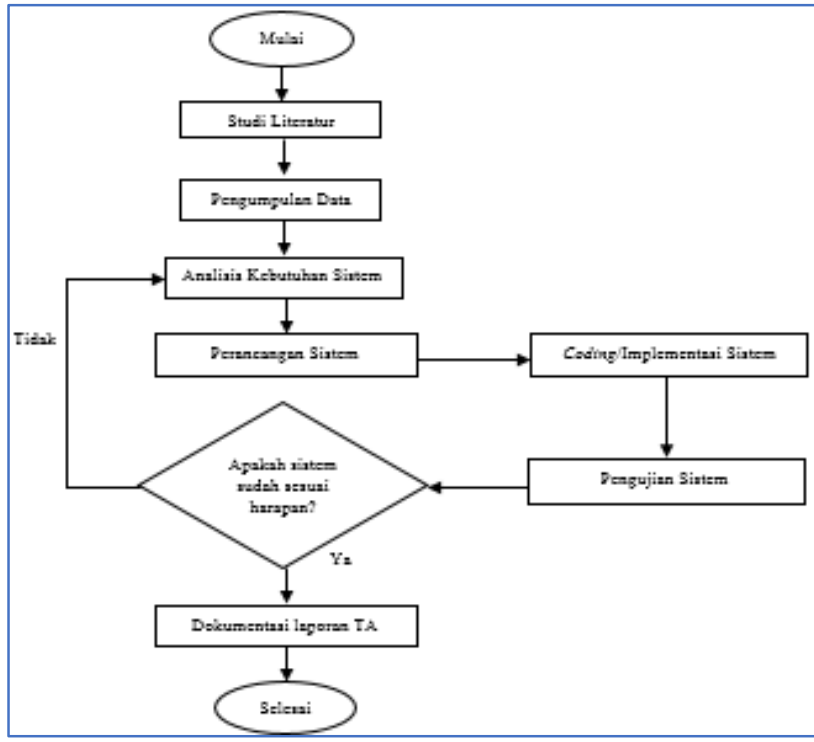

Gambar 1. Diagram alur penelitian. d. Perancangan Sistem KBM yang akan digunakan untuk menganalisa kegiatan belajar mengajar di UNRAM,

e. Implementasi Sitsem KBM berbasis web menggunakan tool Code-Ignitor.

f. Pengujian sistem KBM dilakukan dengan pengujian black-box, Mean Opinion Score.

\subsection{Sistem KBM PSTI UNRAM}

Rancangan sistem analisa tingkat KBM pada PSTI UNRAM disajikan pada Gambar 2.

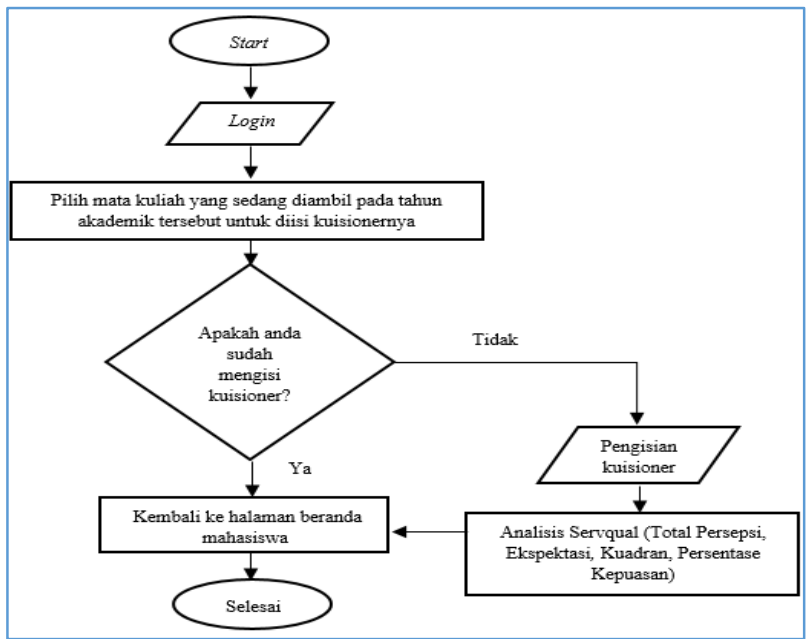

Gambar 2. Diagram alir kerja sistem.

Gambar 2 merupakan diagram alir kinerja sistem KBM, dimana mahasiswa akan melakukan login terlebih dahulu sebelum menggunakan sistem. Setelah ia berhasil login, ia akan diarahkan ke halaman beranda mahasiswa dimana tersedia mata kuliah yang ia ambil pada tahun akademik tersebut. Lalu mahasiswa memilih mata kuliah dan melakukan pengisian kuesioner, dengan memberikan bobot nilai yang sesuai dengan persepsi dan harapan mahasiswa terhadap pelayanan yang diberikan oleh pihak dosen dan PSTI sesuai dengan dimensi pelayanan menurut metode Servqual yang terdiri dari tangibles, emphaty, reliability, responsiveness, dan assurance. Jawaban tersebut nantinya akan diolah dengan perhitungan Servqual untuk mengetahui tingkat kepuasan mahasiswa, yakni dengan melakukan konversi jawaban dari skala nilai yang diberikan oleh mahasiswa berdasarkan persepsi dan harapannya terhadap atribut pelayanan menjadi nilai tertentu yang akan diolah untuk mengetahui posisi kuadran dan kepuasan mahasiswa. Selanjutnya hasil kesimpulan analisa berupa persentase tingkat kepuasan mahasiswa, serta posisi atribut pelayanan berada pada kuadrannya disajikan dalam bentuk laman web. 
Daftar atribut pelayanan yang menjadi pertanyaan pada kuesioner yang harus diisi oleh mahasiswa teknik informatika universitas mataram (TI UNRAM), terdiri dari 5 dimensi pelayanan, dan 50 pertanyaan disajikan pada Tabel I dan II. 15 pertanyaan merupakan kuesioner tentang pelayanan PSTI secara umum, dan 35 pertanyaan merupakan kuesioner yang dikhususkan untuk setiap dosen pengampu mata kuliah.

tabel I. Dimensi Dan Atribut Pelayanan Kbm Pada Psti Unram (UMUM)

\begin{tabular}{|c|c|c|}
\hline $\begin{array}{c}\text { id } \\
\text { pelayanan }\end{array}$ & Dimensi & Pelayanan \\
\hline X01 & \multirow{5}{*}{$\begin{array}{c}\text { Tangibles } \\
\text { (Sarana } \\
\text { pendidikan - } \\
\text { Alat } \\
\text { Perkuliahan, } \\
\text { Media } \\
\text { Pengajaran, } \\
\text { Prasarana } \\
\text { Pendidikan dan } \\
\text { kegiatan } \\
\text { jurusan yang } \\
\text { menunjang } \\
\text { pembelajaran } \\
\text { mahasiswa) }\end{array}$} & $\begin{array}{l}\text { Ruang kuliah nyaman untuk } \\
\text { kegiatan pembelajaran }\end{array}$ \\
\hline $\mathrm{X} 02$ & & $\begin{array}{l}\text { Pada ruang kuliah tersedia sarana } \\
\text { pembelajaran yang memadai }\end{array}$ \\
\hline $\mathrm{X03}$ & & Sarana ruang kuliah berfungsi \\
\hline X04 & & Kebersihan ruangan terjaga \\
\hline X05 & & $\begin{array}{l}\text { Meja dan kursi dalam ruang kelas } \\
\text { cukup untuk kebutuhan kuliah }\end{array}$ \\
\hline $\mathrm{X} 11$ & \multirow{3}{*}{$\begin{array}{c}\text { Emphaty } \\
\text { (Pemahaman } \\
\text { dosen dan } \\
\text { pihak } \\
\text { akademik } \\
\text { terhadap } \\
\text { kepentingan } \\
\text { mahasiswa) }\end{array}$} & $\begin{array}{l}\text { PSTI berusaha memahami minat } \\
\text { dan bakat mahasiswa dan berusaha } \\
\text { untuk mengembangkannya }\end{array}$ \\
\hline $\mathrm{X} 12$ & & $\begin{array}{l}\text { PSTI menyediakan bimbingan } \\
\text { akademik yang baik terhadap } \\
\text { pilihan mata kuliah mana yang } \\
\text { sesuai dengan kebutuhan dan } \\
\text { minat melalui dosen pembimbing } \\
\text { akademik }\end{array}$ \\
\hline $\mathrm{X} 13$ & & $\begin{array}{l}\text { PSTI selalu memonitor kemajuan } \\
\text { mahasiswa melalui dosen } \\
\text { pembimbing akademik }\end{array}$ \\
\hline $\mathrm{X} 21$ & \multirow{2}{*}{$\begin{array}{c}\text { Responsiveness } \\
\text { (Sikap tanggap } \\
\text { dosen dan } \\
\text { pihak } \\
\text { akademik } \\
\text { terhadap } \\
\text { mahasiswa) } \\
\end{array}$} & $\begin{array}{lrr}\text { PSTI menyediakan } & \text { dosen } \\
\text { bimbingan akademik } & \text { bagi } \\
\text { mahasiswa } & & \\
\end{array}$ \\
\hline $\mathrm{X} 22$ & & $\begin{array}{l}\text { PSTI membantu mahasiswa apabila } \\
\text { terdapat masalah akademik }\end{array}$ \\
\hline X41 & \multirow{5}{*}{$\begin{array}{c}\text { Assurance } \\
\text { (Perlakuan } \\
\text { dosen dan } \\
\text { pihak } \\
\text { akademik } \\
\text { terhadap } \\
\text { mahasiswa) }\end{array}$} & $\begin{array}{l}\text { Staf akademik santun dalam } \\
\text { pelayanan akademik }\end{array}$ \\
\hline$X 42$ & & $\begin{array}{l}\text { Permasalahan/keluhan mahasiswa } \\
\text { selalu ditangani oleh PSTI melalui } \\
\text { dosen bimbingan akademik }\end{array}$ \\
\hline X43 & & $\begin{array}{l}\text { PSTI menyediakan fasilitas } \\
\text { laboratorium sistem cerdas untuk } \\
\text { menunjang proses pembelajaran } \\
\text { mahasiswa }\end{array}$ \\
\hline X44 & & $\begin{array}{l}\text { PSTI memberikan layanan wifi } \\
\text { gratis dalam mendukung proses } \\
\text { pembelajaran }\end{array}$ \\
\hline X45 & & $\begin{array}{l}\text { PSTI memberikan sanksi bagi } \\
\text { semua mahasiswa yang melanggar } \\
\text { peraturan yang telah ditetapkan } \\
\text { tanpa terkecuali }\end{array}$ \\
\hline
\end{tabular}

TABel II. Dimensi Dan Atribut Pelayanan Kbm Pada Psti Unram (KHUSUS)

\begin{tabular}{|c|c|c|}
\hline $\begin{array}{c}\text { Id } \\
\text { pelayana } \\
\mathbf{n}\end{array}$ & Dimensi & Pelayanan \\
\hline X06 & \multirow{5}{*}{$\begin{array}{c}\text { Tangibles } \\
\text { (Sarana } \\
\text { pendidikan - } \\
\text { Alat } \\
\text { Perkuliahan, } \\
\text { Media } \\
\text { Pengajaran, } \\
\text { Prasarana } \\
\text { Pendidikan dan } \\
\text { kegiatan } \\
\text { jurusan yang } \\
\text { menunjang } \\
\text { pembelajaran } \\
\text { mahasiswa) }\end{array}$} & $\begin{array}{c}\text { Dosen menyampaikan Rencana } \\
\text { Pembelajaran } \\
\text { Semester/Rencana Tugas } \\
\text { Mahasiswa pada awal semester } \\
\text { perkuliahan }\end{array}$ \\
\hline $\mathrm{X} 07$ & & $\begin{array}{c}\text { Dosen mengaplikasikan Rencana } \\
\text { Pembelajaran } \\
\text { Semester/Rencana Tugas } \\
\text { Mahasiswa dalam } \\
\text { pembelajarannya }\end{array}$ \\
\hline $\mathrm{X} 08$ & & $\begin{array}{c}\text { Materi pembelajaran sesuai } \\
\text { dengan kebutuhan mahasiswa }\end{array}$ \\
\hline X09 & & $\begin{array}{c}\text { Tingkat kesulitan materi } \\
\text { pembelajaran sesuai dengan } \\
\text { tingkat perkembangan } \\
\text { mahasiswa }\end{array}$ \\
\hline $\mathrm{X} 10$ & & $\begin{array}{c}\text { Materi pembelajaran } \\
\text { mendukung kompetensi yang } \\
\text { ingin dicapai mahasiswa }\end{array}$ \\
\hline $\mathrm{X} 14$ & \multirow{7}{*}{$\begin{array}{c}\text { Emphaty } \\
\text { (Pemahaman } \\
\text { dosen dan } \\
\text { pihak } \\
\text { akademik } \\
\text { terhadap } \\
\text { kepentingan } \\
\text { mahasiswa) }\end{array}$} & $\begin{array}{c}\text { Dosen bersedia membantu } \\
\text { mahasiswa yang mengalami } \\
\text { kesulitan studi }\end{array}$ \\
\hline $\mathrm{X} 15$ & & $\begin{array}{c}\text { Dosen memberikan informasi } \\
\text { mengenai informasi lomba, } \\
\text { beasiswa, seminar, lowongan } \\
\text { kerja, dan sejenisnya }\end{array}$ \\
\hline $\mathrm{X} 16$ & & $\begin{array}{c}\text { Dosen memberikan inspirasi dan } \\
\text { memotivasi mahasiswa }\end{array}$ \\
\hline $\mathrm{X} 17$ & & $\begin{array}{c}\text { Dosen memberikan cukup } \\
\text { bimbingan belajar pada mata } \\
\text { kuliah yang bersangkutan }\end{array}$ \\
\hline $\mathrm{X} 18$ & & $\begin{array}{c}\text { Dosen memahami jika } \\
\text { mahasiswa tidak bisa hadir pada } \\
\text { perkuliahan karena sakit } \\
\text { ataupun izin }\end{array}$ \\
\hline X19 & & $\begin{array}{c}\text { Dosen menggunakan waktu } \\
\text { secara efektif dalam proses } \\
\text { pengajaran }\end{array}$ \\
\hline $\mathrm{X} 20$ & & $\begin{array}{c}\text { Dosen memberikan penjelasan } \\
\text { materi perkuliahan dengan } \\
\text { sangat baik dan mudah dipahami }\end{array}$ \\
\hline $\mathrm{X} 23$ & \multirow{6}{*}{$\begin{array}{c}\text { Responsiveness } \\
\text { (Sikap tanggap } \\
\text { dosen dan } \\
\text { pihak } \\
\text { akademik } \\
\text { terhadap } \\
\text { mahasiswa) }\end{array}$} & $\begin{array}{c}\text { Dosen memberi kesempatan } \\
\text { kepada mahasiswa untuk } \\
\text { menyampaikan tanggapan } \\
\text { (misal: bertanya, memberi } \\
\text { komentar, saran) }\end{array}$ \\
\hline $\mathrm{X} 24$ & & $\begin{array}{c}\text { Dosen merespon tanggapan } \\
\text { mahasiswa }\end{array}$ \\
\hline $\mathrm{X} 25$ & & $\begin{array}{c}\text { Dosen menyampaikan informasi } \\
\text { kepada mahasiswa bila } \\
\text { berhalangan hadir }\end{array}$ \\
\hline $\mathrm{X} 26$ & & $\begin{array}{c}\text { Dosen menggantikan } \\
\text { perkuliahan bila berhalangan } \\
\text { hadir }\end{array}$ \\
\hline$\times 27$ & & $\begin{array}{c}\text { Pelaksanaan pembelajaran oleh } \\
\text { dosen mencukupi standar } \\
\text { (minimal 75\%) }\end{array}$ \\
\hline $\mathrm{X} 28$ & & $\begin{array}{c}\text { Dosen memberikan penguatan } \\
\text { (pujian, penghargaan, sanksi) } \\
\text { bagi mahasiswa dalam } \\
\text { pembelajaran }\end{array}$ \\
\hline
\end{tabular}




\begin{tabular}{|c|c|c|}
\hline$\times 29$ & & $\begin{array}{l}\text { Dosen siap melayani mahasiswa } \\
\text { yang ingin berkonsultasi }\end{array}$ \\
\hline X30 & & $\begin{array}{c}\text { Pelaksanaan UTS, UAS dan ujian } \\
\text { lisan (presentasi) yang tepat } \\
\text { waktu sesuai jadwal }\end{array}$ \\
\hline X31 & \multirow{10}{*}{$\begin{array}{l}\text { Reliability } \\
\text { (Kehandalan } \\
\text { dosen dan } \\
\text { pihak } \\
\text { akademik) }\end{array}$} & $\begin{array}{c}\text { Dosen menguasai materi } \\
\text { pembelajaran }\end{array}$ \\
\hline X32 & & $\begin{array}{l}\text { Dosen menggunakan sumber- } \\
\text { sumber materi yang up-to-date }\end{array}$ \\
\hline X33 & & $\begin{array}{c}\text { Dosen mampu mengelola kelas } \\
\text { dengan baik }\end{array}$ \\
\hline X34 & & $\begin{array}{l}\text { Dosen mampu membangkitkan } \\
\text { motivasi belajar mahasiswa }\end{array}$ \\
\hline X35 & & $\begin{array}{l}\text { Dosen menggunakan metode } \\
\text { pembelajaran yang bervariasi } \\
\text { (misal: penugasan, presentasi, } \\
\text { diskusi, studi lapangan, dll.) }\end{array}$ \\
\hline X36 & & $\begin{array}{l}\text { Dosen menggunakan alat } \\
\text { pembelajaran (misal: } \\
\text { whiteboard, LCD, speaker, } \\
\text { pointer, smartboard, dII.) }\end{array}$ \\
\hline X37 & & $\begin{array}{c}\text { Dosen melaksanakan } \\
\text { perkuliahan sesuai dengan } \\
\text { jadwal }\end{array}$ \\
\hline X38 & & $\begin{array}{c}\text { Dosen melaksanakan evaluasi } \\
\text { sesuai dengan } \\
\text { indikator/kompetensi } \\
\text { pembelajaran }\end{array}$ \\
\hline X39 & & $\begin{array}{c}\text { Dosen } \\
\text { mendampingi/membimbing } \\
\text { diskusi mahasiswa dan } \\
\text { memberika solusi jika ada } \\
\text { permasalahan } \\
\end{array}$ \\
\hline $\mathrm{X} 40$ & & $\begin{array}{c}\text { Dosen memberikan balikan } \\
\text { terhadap proses hasil diskusi, } \\
\text { tugas, kuis, ujian yang telah } \\
\text { dikoreksi } \\
\end{array}$ \\
\hline $\mathrm{X} 46$ & \multirow{2}{*}{$\begin{array}{c}\text { Assurance } \\
\text { (Perlakuan } \\
\text { dosen dan } \\
\text { pihak } \\
\text { akademik } \\
\text { terhadap } \\
\text { mahasiswa) }\end{array}$} & $\begin{array}{c}\text { Tanggung jawab dalam } \\
\text { mengolah nilai akhir mahasiswa } \\
\text { dilakukan oleh dosen/tim dosen } \\
\text { bersama-sama }\end{array}$ \\
\hline $\mathrm{X} 47$ & & $\begin{array}{l}\text { Refleksi hasil belajar (tugas, kuis, } \\
\text { ujian dan hasil praktikum) } \\
\text { dilakukan oleh dosen/tim dosen } \\
\text { secara konsisten }\end{array}$ \\
\hline $\mathrm{X} 48$ & & $\begin{array}{c}\text { Dosen memberikan kesempatan } \\
\text { pada mahasiswa untuk } \\
\text { mengikuti ujian susulan jika ia } \\
\text { tidak bisa hadir karena sakit atau } \\
\text { alasan yang jelas }\end{array}$ \\
\hline $\mathrm{X} 49$ & & $\begin{array}{c}\text { Dosen memberikan balikan } \\
\text { terhadap proses hasil diskusi, } \\
\text { tugas, quiz, ujian yang telah } \\
\text { dikoreksi }\end{array}$ \\
\hline $\mathrm{X} 50$ & & $\begin{array}{l}\text { Waktu dipergunakan secara } \\
\text { efektif oleh dosen dalam proses } \\
\text { pembelajaran }\end{array}$ \\
\hline
\end{tabular}

\subsubsection{Usecase Sistem KBM PSTI UNRAM}

Usecase digunakan untuk menggambarkan proses analisa KBM yang dilakukan oleh pengguna sistem. Rancangan usecase sistem Usecase Sistem KBM PSTI UNRAM disajikan pada Gambar 3, yang mengilustrasikan interaksi pengguna dengan sistem. Sistem ini memiliki 4 pengguna yakni operator, ketua program studi (kaprodi), dosen, dan mahasiswa. Operator dapat mengelola data mahasiswa, dosen, kuesioner, dan data hasil analisa kepuasan mahasiswa seperti menambah, menghapus, mengubah, melihat, dan mencetak data. Kaprodi dan Dosen dapat mengubah password, melihat hasil analisa tingkat kepuasan mahasiswa serta mencetak hasil analisa. Mahasiswa dapat mengubah password dan mengisi kuesioner penilaian. Untuk melakukan operasi tersebut baik operator, kaprodi, dosen, dan mahasiswa harus melakukan login dahulu.

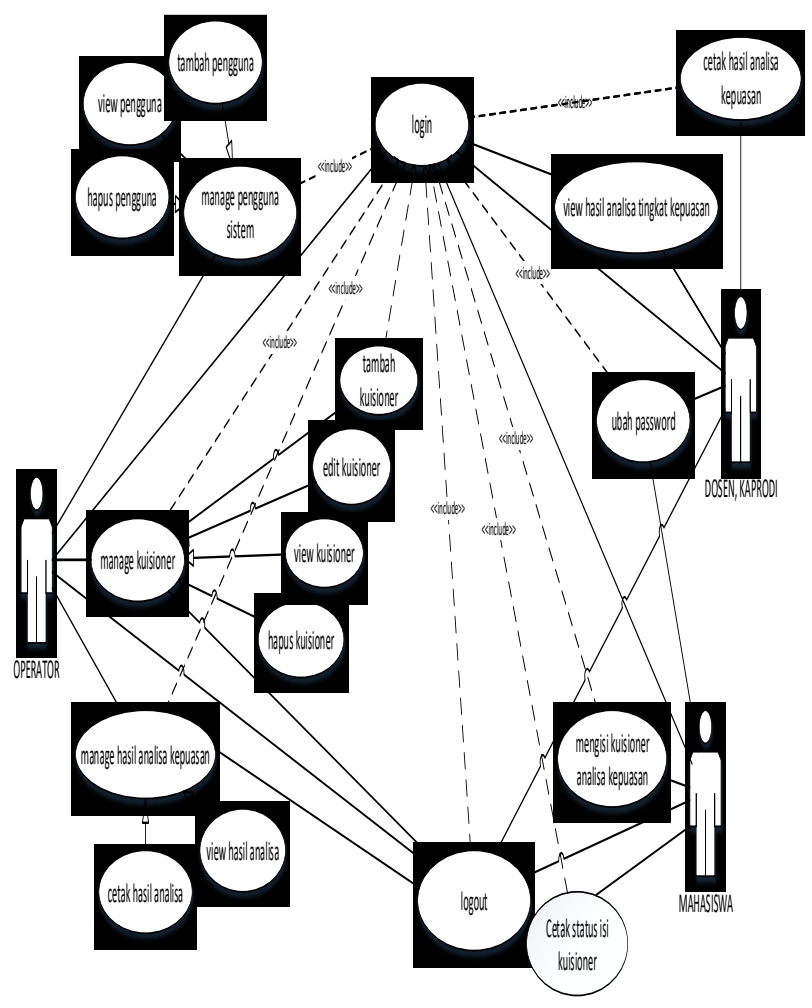

Gambar 3. Perancangan usecase.

\subsubsection{Rancangan Database}

Tabel-tabel yang terdiri dari field-field yang dibutuhkan dalam pemrosesan data pada sistem KBM dan hubungannya dituangkan kedalam rancangan database seperti disajikan pada Gambar 4. Rancangan database kuesioner terdiri dari 5 tabel yang saling berelasi, yaitu tabel pengguna_sistem, tabel mengisi, tabel tb_kuesioner, tabel hasilanalisaServqual dan tabel tb_tampung.

Pada tabel pengguna_sistem memiliki empat field yaitu nomorinduk, password level dan photo. Tabel ini berfungsi untuk menyimpan data pengguna sistem yang akan digunakan untuk mengakses sistem dengan melakukan login. Dimana pengguna sistem ini terdiri dari operator, kepala program studi, dosen, dan juga mahasiswa. Fungsi pengguna sistem berbeda-beda sesuai hak akses (level) yang sudah ditentukan. 


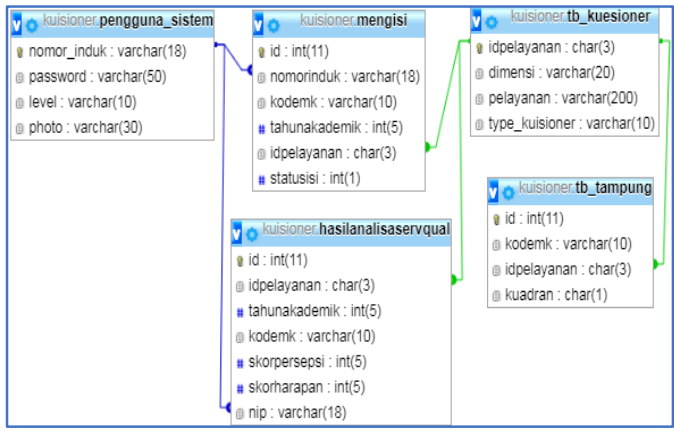

Gambar 4. Perancangan database.

Pada tabel tb_kuesioner memiliki empat field yaitu idpelayanan, dimensi, pelayanan, dan type_kuesioner. Tabel ini berfungsi untuk menyimpan seluruh data kuesioner mengenai tingkat kepuasan belajar mengajar mahasiswa pada sistem.

Pada tabel mengisi memiliki enam field yaitu id, nomorinduk, kodemk, tahunakademik, idpelayanan, dan status isi. Tabel ini berfungsi untuk menyimpan seluruh data dari pengguna sistem yaitu mahasiswa yang telah melakukan pengisian kuesioner.

Pada tabel hasilanalisaServqual memiliki tujuh field yaitu id, idpelayanan, tahunakademik, kodemk, skorpersepsi, skorharapan, dan nip. Tabel ini berfungsi untuk menyimpan seluruh data hasil analisa tingkat kepuasan mahasiswa yang sudah melakukan pengisian kuesioner.

Pada tabel tb_tampung memiliki empat field yaitu id, kodemk, idpelayanan, dan kuadran. Tabel ini berfungsi untuk menyimpan seluruh data kuadran di masing-masing mata kuliah.

\subsection{Prosedur Metode Servqual untuk Analisa KBM}

Mula-mula mahasiswa mengisi kuesioner pada masing-masing mata kuliah yang sedang ia tempuh secara online. salah satu contoh halaman pengisian kuesioner oleh mahasiswa seperti pada Gambar 5. Kuesioner berisi dimensi pelayanan, dan atribut palayanan, serta skor penilaian pada masing masing atribut pelayanan, terdiri dari skor 1 sampai 5 yang harus diisi oleh mahasiswa berdasarkan penilaiannya terhadap pelayanan selama proses kegiatan belajar mengajar berlangsung secara jujur dan objektif.

Adapun langkah-langkah perhitungan Metode Servqual[7] atas data hasil kuesioner adalah sebagai berikut :

1. Menghitung skor nilai dari tingkat persepsi dan tingkat harapan pelanggan terhadap atribut pelayanan:

a. Menghitung skor persepsi pelayanan dengan Persamaan (1)

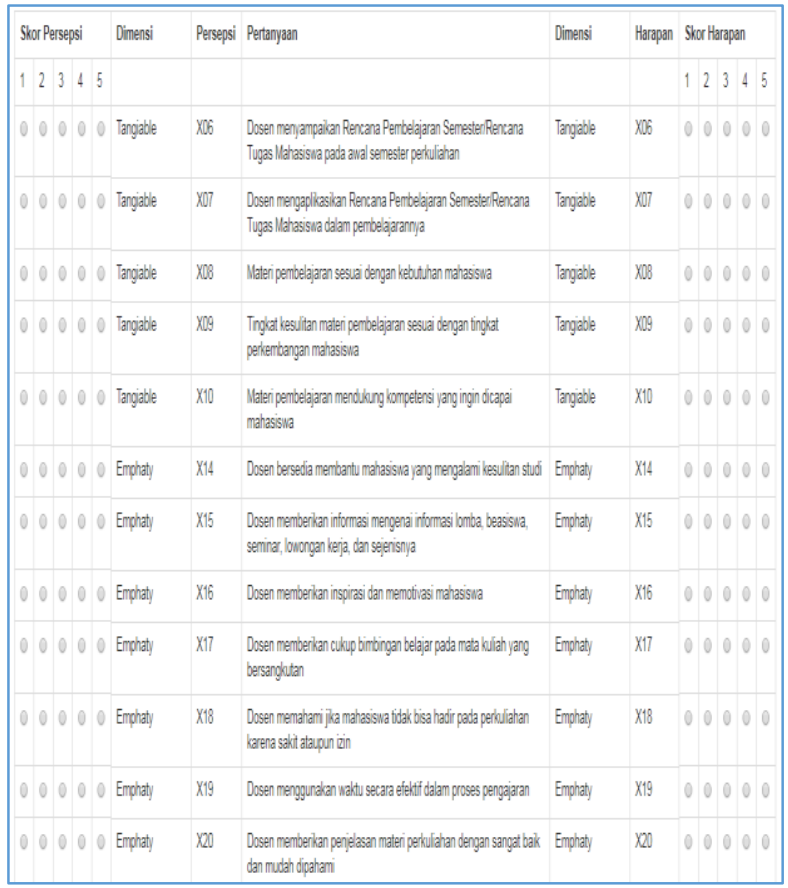

Gambar 5. Halaman pengisian kuisioner

$\sum X_{i}=\sum T_{p}+2 \sum K_{p}+3 \sum C_{p}+4 \sum P+5 \sum S_{p}(1$

dimana :

$\sum X_{i p}=$ Skor persepsi per atribut pelayanan,

$\sum T_{p}=$ Jumlah penilaian persepsi tidak puas,

$\sum K_{p}=$ Jumlah penilaian persepsi kurang puas,

$\sum C_{p}=$ Jumlah penilaian persepsi cukup puas,

$\sum P=$ Jumlah penilaian persepsi puas,

$\sum S_{p}=$ Jumlah penilaian persepsi sangat puas, dan

Koefieien menunjukkan skor skala masingmasing persepsi.

b. Menghitung skor harapan pelayanan dengan Persamaan (2) :

$\sum Y_{i}=\sum T_{h}+2 \sum K_{h}+3 \sum C_{h}+4 \sum P_{h}+5 \sum S_{h}(2)$ dimana :

$\sum Y_{i}=$ Skor harapan per atribut pelayanan,

$\sum T_{h}=$ Jumlah penilaian harapan tidak puas,

$\sum K_{h}=$ Jumlah penilaian harapan kurang puas,

$\sum C_{h}=$ Jumlah penilaian harapan cukup puas,

$\sum P=$ Jumlah penilaian harapan puas,

$\sum S_{p}=$ Jumlah penilaian harapan sangat puas, dan

Koefieien menunjukkan skor skala masingmasing harapan.

2. Setelah itu, dihitung skor rata-rata persepsi $(\vec{X})$ dan skor rata-rata harapan $(\vec{Y})$ dalam Persamaan (3) dan (4) :

$$
\vec{X}=\frac{\sum X i}{n}
$$




$$
\overrightarrow{\mathrm{Y}}=\frac{\sum \mathrm{Yi}}{\mathrm{n}}
$$

dimana :

$\overrightarrow{\mathrm{X}} \quad=$ Nilai rata-rata skor persepsi,

$\sum \mathrm{Xi}=$ Jumlah total skor persepsi,

$\overrightarrow{\mathrm{Y}} \quad=$ Nilai rata-rata skor harapan,

$\sum \mathrm{Yi}=$ Jumlah total skor harapan, dan

$\mathrm{n} \quad$ = Jumlah responden.

3. Menentukan nilai hasil atribut pelayanan ke dalam kuadran A, B, C, D (Gambar 6) tujuannya yaitu untuk menentukan urutan prioritas pelayanan yang mempengaruhi kepuasan mahasiswa terhadap KBM pada PSTI Universitas Mataram. untuk mencari nilai titik potong $X$ (rata-rata persepsi) dan Y (rata-rata harapan) dilakukan dengan cara menjumlahkan semua total rata-rata persepsi dan total rata-rata harapan lalu sama sama dibagi dengan 50 (jumlah atribut pelayanan).

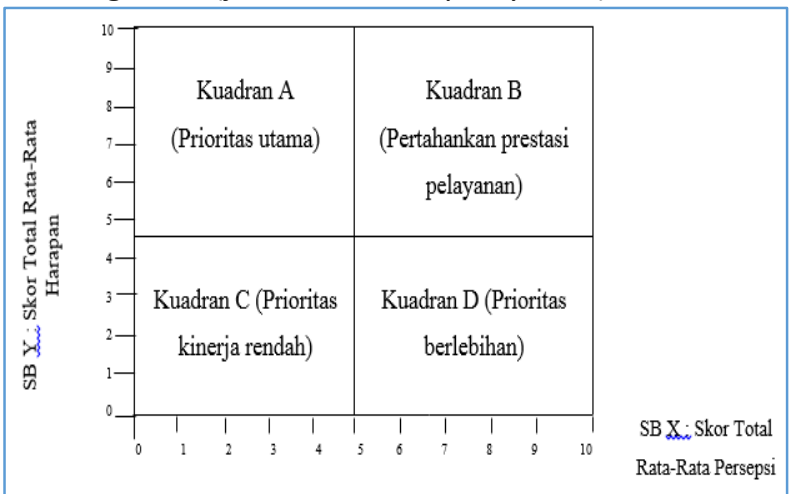

Gambar 6. Diagram kartesius.

Makna dari masing-masing kuadaral adalah sebgai berikut :

a. Kuadran A menyatakan bahwa atribut dianggap sangat penting, tapi kinerja rendah, sehingga mahasiswa tidak puas (Menjadi Prioritas Utama Dalam Perbaikan),

b. Kuadran B menyatakan bahwa atribut dianggap sangat penting, kinerja sudah bagus. Mahasiswa puas, sehingga wajib dipertahankan (Pertahankan prestasi pelayanan).

c. Kuadran C menyatakan bahwa atribut dianggap kurang penting, kinerja biasa saja, persepsi dan harapan sama sama rendah, sehingga dianggap kurang memuaskan oleh mahasiswa (Prioritas rendah).

d. Kuadran D menyatakan bahwa mahasiswa puas, kinerja tinggi, tetapi sebenarnyaharapan lebih rendah dari itu (Prioritas berlebihan).

4. Menghitung Tingkat Kesesuaian Responden dengan menggunakan Persamaan (5).

$$
\mathrm{Tki}=\frac{\sum \mathrm{Xi}}{\sum \mathrm{Yi}} \times 100 \%
$$

dimana :

$\mathrm{Tk}_{\mathrm{i}}=$ Tingkat kesesuaian responden,

$\sum \mathrm{X}_{\mathrm{i}}=$ Jumlah total skor persepsi, dan

$\sum \mathrm{Y}_{\mathrm{i}}=$ Jumlah total skor harapan.

5. Hasil Tingkat Kesesuaian Responden disesuaikan dengan Tabel III.

tABEL III. Persentase Tingkat Kesesuaian Responden Sebagal Indeks KePuasan Mahasiswa [6]

\begin{tabular}{|c|c|c|}
\hline No & Tki & Keterangan \\
\hline 1 & $85 \% \leq x \leq 100 \%$ & $\begin{array}{c}\text { Sangat baik / Sangat } \\
\text { puas }\end{array}$ \\
\hline 2 & $70 \% \leq x<85 \%$ & Baik / Puas \\
\hline 3 & $55 \% \leq x<70 \%$ & Cukup baik / Cukup puas \\
\hline 4 & $40 \% \leq x<55 \%$ & $\begin{array}{c}\text { Kurang baik / Kurang } \\
\text { puas }\end{array}$ \\
\hline 5 & $25 \% \leq x<40 \%$ & $\begin{array}{c}\text { Sangat kurang baik / } \\
\text { Sangat kurang puas }\end{array}$ \\
\hline
\end{tabular}

\section{HASIL DAN IMPLEMENTASI}

\subsection{Implementasi}

Implementasi sistem KBM terdiri atas beberapa interface yang disesuaikan dengan pengguna sistem yiatu halaman Operator, halaman Ketua Program Studi Teknik Informatika Universitas Mataram (KaProdi TI UNRAM), halaman Dosen, dan juga halaman bagi Mahasiswa. Contoh Interface sistem KBM disajikan pada Gambar 7 dan Gambar 8.

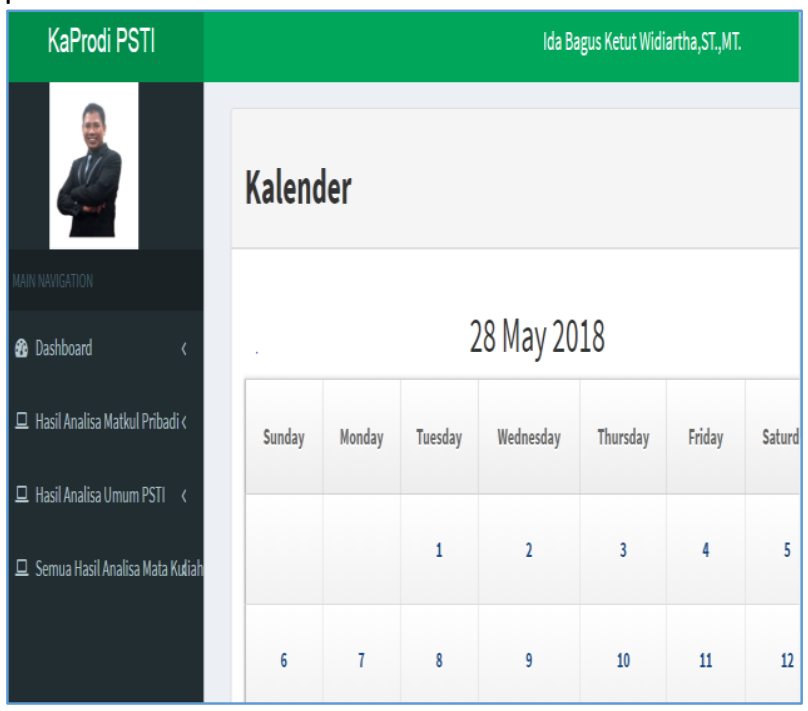

Gambar 7. Halaman kaprodi.

Gambar 7 merupakan halaman Kepala program studi (KProdi), dimana terdapat dashboard hasil analisa kepuasan mahasiswa berdasarkan mata kuliah yang diampunya, hasil analisa kepuasan mahasiswa dari 
semua dosen, dan hasil analisa kepuasan mahasiswa secara umum terhadap pelayanan PSTI UNRAM. KaProdi dapat melihat dan mencetak hasil analisa, dan melakukan pengubahan foto dan passwordnya.

\begin{tabular}{|c|c|c|c|}
\hline No & NIP & Nama Dosen & Action \\
\hline 1 & 196604032006042001 & Ir. Sri Endang Anjarwani, M.Kom & Hapus \\
\hline 2 & 197005141999031002 & Ida Bagus Ketut Widiartha,ST.,MT. & Hapus \\
\hline 3 & 197210191999032001 & DR.Eng. Budi Irmawati. S.Kom.,MT. & Hapus \\
\hline 4 & 197311302000031001 & I Gede Pasek Suta Wijaya, ST., MT., D.Eng. & Hapus \\
\hline 5 & 197506122000031001 & Heri Wijayanto, ST.,MT. & Hapus \\
\hline 6 & 198211182015041001 & I Wayan Agus Arimbawa, ST., M.Eng & Hapus \\
\hline 7 & 198311252015041002 & Moh. Ali Albar, ST., M.Eng. & Hapus \\
\hline 8 & 198312092012121001 & Andy Hidayat Jatmika, S.T., M.Kom. & Hapus \\
\hline 9 & 198507072014042001 & Royana Afwani, ST., MT. & Hapus \\
\hline 10 & 198606222015041002 & Fitri Bimantoro, ST.,M.Kom. & Hapus \\
\hline 11 & 198609132015041001 & Ariyan Zubaidi, S.Kom., MT & Hapus \\
\hline 12 & 199012182012121002 & Ario Yudo Husodo, ST.,MT. & Hapus \\
\hline & Data & & \\
\hline
\end{tabular}

Gambar 8. Halaman data dosen.

Gambar 8 merupakan halaman data dosen yang terletak pada halaman operator, dimana terdapat NIP dan nama dosen program studi teknik informatika universitas mataram.

Berikut ini merupakan implementasi dari langkahlangkah perhitungan analisa tingkat kepuasan mahasiswa dengan menggunakan metode Servqual dengan jumlah sampel mahasiswa yang mengisi kuesioner sebanyak 40 orang mahasiswa dan atribut pelayanan yang terdiri dari id pelayanan X01 sampai dengan X50. Dari data sampel tersebut diperoleh hasil nilai titik potong $X$ (rata-rata persepsi) dan $Y$ (rata-rata harapan) atas total rata-rata persepsi (173.00) dan total rata-rata harapan (229) dibagi dengan 50 (jumlah atribut pelayanan), yaitu $\vec{X}=3,45$ dan $\vec{Y}=4,57$, secara berurutan. Selanjutnya dari nilai $\vec{X}=3,45$ dan $\overrightarrow{\mathrm{Y}}=4,57$, maka posisi kuadran dari atribut pelayanan $\left(X_{i j}\right)$ dapat ditentukan dengan aturan:

1. Jika $\overrightarrow{\mathrm{Y}}<X_{i j} \leq \overrightarrow{\mathrm{X}}$, maka atribut pelayanan tersebut berada pada kuadran A (Prioritas utama).

2. Jika $\overrightarrow{\mathrm{Y}}<X_{i j}>\overrightarrow{\mathrm{X}}$, maka atribut pelayanan tersebut berada pada kuadran $B$ (Pertahankan prestasi).

3. Jika $\overrightarrow{\mathrm{Y}} \geq X_{i j} \leq \overrightarrow{\mathrm{X}}$, maka atribut pelayanan tersebut berada pada kuadran $C$ (Prioritas rendah).

4. Jika $\overrightarrow{\mathrm{Y}} \geq X_{i j}>\overrightarrow{\mathrm{X}}$, maka atribut pelayanan tersebut berada pada kuadran $\mathrm{D}$ (Prioritas berlebihan)

Diperoleh juga total indeks kepuasan mahasiswa (Tingkat kesesuaian responden, Tki) secara keseluruhan sebesar $75,51 \%$ yang dihitung dengan Persamaan 5 dengan skor total persepsi sebesar 6.903, dan skor total harapan sebesar 9.141. Berdasarkan tabel referensi (Tabel II), maka nilia 75,51\% menunjukkan mahasiswa merasa Puas dengan pelayanan selama proses kegiatan belajar mengajar pada program studi teknik informatika universitas mataram.

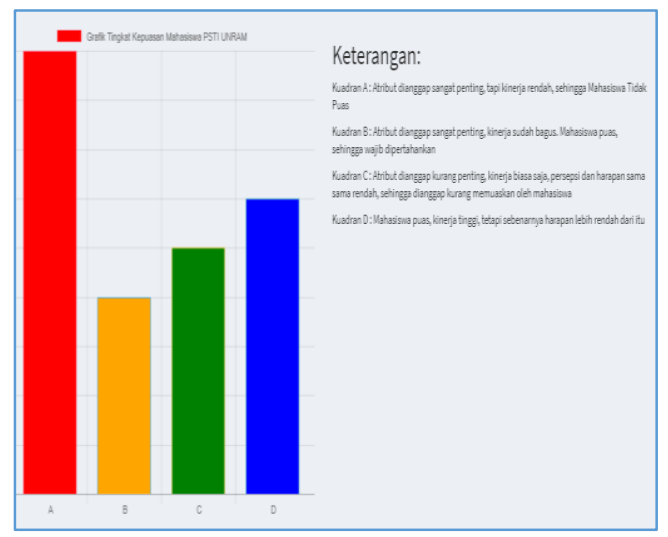

Gambar 9. View hasil analisa mata kuliah

1.

Gambar 13 merupakan halaman view grafik hasil analisa tingkat kepuasan mahasiswa pada salah satu mata kuliah, dimana terlihat nilai yang mendominasi penilaian pada mata kuliah tersebut adalah kuadran B.

\subsection{Pengujian Sistem}

\subsubsection{Pengujian Black Box}

Pengujian Black Box adalah pengujian yang dilakukan dengan cara menguji sistem dari segi spesifikasi fungsional dengan memberikan input tertentu dan melihat hasil yang didapatkan dari input tersebut. Pengujian dimaksudkan untuk mengetahui apakah fungsi-fungsi, masukan, dan keluaran dari sistem yang dibuat telah sesuai dengan spesifikasi yang dibutuhkan. Dari 30 kali pengujian bahwa hasil data yang diharapkan dengan hasil data yang dikeluarkan oleh sistem adalah sesuai maka dapat disimpulkan bahwa fungsionalitias dari sistem KBM telah berjalan sebagaimana mestinya.

\subsubsection{Pengujian MOS (Mean Opinion Score)}

Pengujian MOS digunakan untuk mengetahui respon penilaian secara subjektif dari responden terhadap sistem yang dibuat berdasarkan pengamatan hasil survey. Adapun yang akan dinilai adalah dari segi kemudahan penggunaan sistem, dan tampilan sistem.

Pengujian ini dilakukan oleh 40 responden yang terdiri dari 8 pertanyaan, yaitu :

1. Sistem ini mudah digunakan?

2. Sistem ini memiliki kecocokan font, warna, dan style di setiap halaman? 
3. Sistem ini memiliki kecocokan antara background dengan foreground?

4. Navigasi dan menu pada sistem ini cukup sederhana dan mudah digunakan?

5. Loading yang cepat ( $<5$ detik) dalam menggunakan sistem ini?

6. Tampilan dan desain sistem ini sederhana dan menarik?

7. Soal kuisioner pada sistem sangat relefan dengan kegiatan belajar mengajar bersama dosen

8. Sistem ini dapat memberikan informasi tingkat kepuasan mahasiswa terhadap kegiatan belajar mengajar di Program Studi Teknik Informatika Universitas Mataram?

Berdasarkan pertanyaan yang ada, 40 orang responden (mahasiswa) diminta untuk menjawab dengan skor penilaian antara 1-5 seperti nilai pada Tabel III

TABEL III. Standar Penilaian MOS[8]

\begin{tabular}{|c|c|c|}
\hline Nilai MOS & Tingkat Kepuasan & Kelompok \\
\hline 5 & Sangat Setuju & Sangat Baik \\
\hline 4 & Setuju & Baik \\
\hline 3 & Netral & $\begin{array}{c}\text { Cukup Baik } \\
\text { (Netral) }\end{array}$ \\
\hline 2 & Tidak Setuju & Tidak Baik \\
\hline 1 & Tidak Setuju & Buruk \\
\hline
\end{tabular}

Berdasarkan jawaban responden pada kuisioner tersebut, dilakukan perhitungan skor total rata-rata jawaban dari setiap atribut pertanyaan dengan menggunakan Persamaan (6).

$$
\text { Mean } \mathrm{Pi}=\frac{\sum \mathrm{Pi}}{\mathrm{N}}
$$

dimana :

Mean $\mathrm{Pi}=$ Rata-rata skor setiap atribut pertanyaan,

$\mathrm{Pi}=$ Jumlah skor dikalikan bobot setiap atribut Pertanyaan, dan

$\mathrm{N} \quad=$ Jumlah responden.

Selanjutnya, hasil dari perhitungan skor total ratarata jawaban dari setiap atribut pertanyaan tersebut akan digunakan untuk mencari MOS (Mean Opinion Score) dengan Persamaan (7).

$$
\text { MOS }=\frac{\sum_{i=1}^{\mathrm{k}} \text { Mean } \mathrm{Pi}}{\mathrm{k}}
$$

dimana :

MOS = Total skor rata-rata seluruh atribut pertanyaan, $\mathrm{k} \quad$ = Jumlah atribut pertanyaan.

Adapun hasil perhitungan pengujian MOS dari jawaban responden terhadap kuisioner dapat dilihat pada Tabel IV.
TABEL IV. HASIL PENGUJIAN MOS

\begin{tabular}{|c|c|c|c|c|c|c|c|}
\hline No & Pertanyaan & $\begin{array}{c}\text { SS } \\
\mathbf{( 5 )}\end{array}$ & $\begin{array}{c}\text { S } \\
\mathbf{( 4 )}\end{array}$ & $\begin{array}{c}\text { N } \\
\mathbf{( 3 )}\end{array}$ & $\begin{array}{c}\text { TS } \\
\mathbf{( 2 )}\end{array}$ & $\begin{array}{c}\text { STS } \\
(\mathbf{1})\end{array}$ & Mean \\
\hline 1 & Pertanyaan 1 & 15 & 20 & 5 & 0 & 0 & 4.25 \\
\hline 2 & Pertanyaan 2 & 12 & 18 & 10 & 0 & 0 & 4.05 \\
\hline 3 & Pertanyaan 3 & 7 & 25 & 8 & 0 & 0 & 3.98 \\
\hline 4 & Pertanyaan 4 & 10 & 25 & 5 & 0 & 0 & 4.13 \\
\hline 5 & Pertanyaan 5 & 12 & 19 & 9 & 0 & 0 & 4.08 \\
\hline 6 & Pertanyaan 6 & 11 & 24 & 5 & 0 & 0 & 4.15 \\
\hline 7 & Pertanyaan 7 & 19 & 19 & 2 & 0 & 0 & 4.43 \\
\hline 8 & Pertanyaan 8 & 12 & 23 & 5 & 0 & 0 & 4.18 \\
\hline \multicolumn{7}{|c|}{ MOS (Mean Opinion Score) } \\
\hline
\end{tabular}

Berdasarkan hasil pengujian MOS yang dilakukan oleh 40 responden dengan 8 butir pertanyaan maka didapatkan nilai rata-rata MOS sebesar $=4,15$ yang dikategorikan dalam kelompok "Baik" sesuai dengan ststandar Tabel III.

\section{Kesimpulan Dan SARAN}

\subsection{Kesimpulan}

Berdasarkan pembahasan sebelumnya maka dapat disimpulkan bahwa :

1. Berdasarkan pengujian black box, semua fitur yang ada pada sistem sudah sesuai dengan rancangan yang dibuat.

2. Persentase hasil analisa tingkat kepuasan mahasiswa terhadap KBM pada PSTI UNRAM menggunakan metode Servqual sebesar $75,51 \%$, dengan sampel sebanyak 40 orang mahasiswa.

3. Berdasarkan nilai MOS oleh 40 responden (mahasiswa) adalah sebesar 4,15 dan dikategorikan dalam kelompok baik, yang menunjukkan bahwa sistem telah berjalan dengan baik dan sudah sesuai dengan harapan.

\subsection{Saran}

Adapun saran yang diberikan sebagai berikut :

1. Agar data hasil analisa dapat dipastikan lengkap, mahasiswa diwajibkan untuk mengisi kuesioner mata kuliah yang diprogramkan pada semester tersebut sebagai syarat agar nilai mata kuliah dapat ditampilkan pada KHS.

2. Agar PSTI UNRAM dapat memberikan pelayanan KBM dengan kualitas yang lebih baik lagi, perlu adanya evaluasi kinerja dalam rangka peningkatan performa setiap pelayanan yang skor penilaiannya masih jauh dari harapan mahasiswa.

3. Agar sistem analisa tingkat kepuasan mahasiswa terhadap KBM ini dapat dikembangkan menjadi lebih kompleks 
mencangkup se-fakultas teknik maupun seuniversitas mataram dengan menggunakan metode-metode lainnya dengan tampilan yang lebih bagus lagi.

\section{DAfTAR PUstaka}

[1]. Sujatmiko., P.S. Budi, R. Soenoko, dan M. Astuti, "Upaya Peningkatan Pelayanan Terhadap Kepuasan Mahasiswa Berdasarkan Hasil Analisi Metode Servqual dan Regresi Linear Berganda," Fakultas Teknik Universitas Brawijaya, Malang, 2013.

[2]. D.G. Febrian, “Analisa Kepuasan Mahasiswa Terhadap Kegiatan Belajar Mengajar Di Program Studi Teknik Informatika Universitas Mataram Menggunakan Metode Importance Performance Analysis," Fakultas Teknik Program Studi Informatika Univesitas Mataram, Mataram, 2017.

[3]. A.T. Sambodo, dan H.B. Dirgantara, H.B, "Analisis Kepuasan Konsumen dengan Servqual Studi Kasus Media Sosial bhinneka.com," Fakultas Ilmu Komputer dan IImu Komunikasi Kalbis Institut, Jakarta Timur, 2014.
[4]. A.D. Sugirahardja, I. Santoso, dan S. Anggarini, "Pengukuran Tingkat Kepuasan Pelanggan Terhadap Kualitas Pelayanan Dengan Metode Servqual Studi Kasus Pada Pusat Oleh-Oleh Harum Manis," Fakultas Pertanian Universitas Brawijaya, Malang, 2015.

[5]. R. Firliana, P. Kasih, dan H.S. Sulastri, "Sistem Analisa Kualitas Pelayanan Terhadap Tingkat Kepuasan Pelanggan Menggunakan Metode Service Qualit (Servqual)," Universitas Nusantara PGRI, Kediri, 2016.

[6]. I.G.A.M. Srinadi, dan D.P.E. Nilakusmawati, "FaktorFaktor Penentu Kepuasan Mahasiswa Terhadap Pelayanan Fakultas Sebagai Lembaga Pendidikan," FMIPA Universitas Udayana, Bali, 2008.

[7]. B. Harto, "Analisis tingkat kepuasan pelanggan dengan pendekatan fuzzy servqual dalam upaya peningkatan kualitas pelayanan (studi kasus di bengkel resmi bajaj padang)," Jurnal Teknolf, vol. 3, no. 1, pp -, 2015.

[8]. G.A. Putra, Endroyono, dan G. Kusrahardjo, "Rancang Bangun Software Sistem Monitoring TV Digital DVBT2," Fakultas Teknologi Industri, Institut Teknologi Sepuluh Nopember (ITS), Surabaya, 2015. 